www.jmscr.igmpublication.org

Impact Factor (SJIF): 6.379

Index Copernicus Value: 79.54

ISSN (e)-2347-176x ISSN (p) 2455-0450

crossrefDOI: https://dx.doi.org/10.18535/jmscr/v6i8.98

Journal Of Medical Science And Clinical Research

\title{
Immature Platelet Fraction as a Prognostic Indicator of Platelet Recovery in Patients with Thrombocytopenia - An Observational Study
}

Authors

\author{
Roshan Paul Mampilly ${ }^{1}$, Jerry George Earali ${ }^{2}$, Anil Kumar CR ${ }^{3}$, Joe Thomas ${ }^{4}$ \\ ${ }^{1}$ Junior Resident, Department of Medicine, JMMC and RI, Thrissur \\ ${ }^{2}$ Professor, Department of Medicine, JMMC and RI, Thrissur \\ ${ }^{3,4}$ Associate Professor, Department of Medicine, JMMC and RI, Thrissur
}

\begin{abstract}
Background \& Objectives: Immature Platelets or Reticulated Platelets $(R P)$ are newly released platelets which are larger and more reactive than mature platelets and contain RNA. Immature Platelet Fraction $(I P F)$ is the percentage of RPs. It reflects the severity of damage to platelets and the generation of platelets in bone marrow. The objective of the study was to assess whether IPF could potentially be used as a prognostic indicator of platelet recovery in patients with thrombocytopenia.

Methods: This is a prospective observational study in 141 eligible patients who were followed up over a period of 5 days. Serial monitoring of platelet count and IPF were conducted on $1^{\text {st }}, 3^{\text {rd }}$ and $5^{\text {th }}$ day. An IPF value of $>6.1 \%$ was considered as high. An increase of platelet count of 20,000 cells/ $\mu L$ was considered as significant. The study population was grouped based on clinical diagnosis, aetiology of thrombocytopenia and severity of thrombocytopenia. Descriptive and inference analysis were done. Correlation between change in platelet count with respect to change in IPF was analysed.

Results and Discussion: Of 141 patients $68.1 \%$ were males and $31.9 \%$ were females. Majority of the patients belonged to age group 21-40 years (42.6\%). Dengue was diagnosed in $68.1 \%$ of the total patients. Pearson correlation coefficient between change in IPF and change in platelet counts on dayl, day 3 and day 5 were $-0.393,-0.455$ and -0.393 respectively. IPF had an inverse correlation with respect to platelet counts. p-value obtained was $<0.001$ which was statistically significant. Kruskal-Wallis Test was done to find if there is any significant difference in IPF among the aetiologies. The p-value obtained was 0.003 which was statistically significant. Hence pair wise comparison of different aetiologies was done. It was found that peripheral destruction of platelets had a significant association with IPF compared to all other aetiologies.

Conclusion: There was a moderate inverse correlation between IPF and platelet counts. As the IPF levels fell, platelet levels tended to increase. It had some predictive value in anticipating platelet recovery. In thrombocytopenia, due to peripheral destruction IPF can potentially be used as a screening test.
\end{abstract}




\section{Introduction}

Normal platelet count is defined as, being between $150,000-400,000$ cells $/ \mu \mathrm{L}^{(1)}$. Hence, thrombocytopenia can be defined as platelet count below 150,000 cells $/ \mu \mathrm{L}$. Thrombocytopenia results from decreased marrow production, sequestration in an enlarged spleen and increased platelet destruction. Thus, the aetiology being multifactorial, causes may be congenital, infective, drug induced and others $^{(1)}$.

In severe thrombocytopenia, where platelet levels are $<20,000$ cells $/ \mu \mathrm{L}$, the risk of morbidity and mortality increases dramatically. In severe cases, which can lead to life threatening haemorrhages (e.g. intracranial bleed), often the mode of management is platelet transfusion ${ }^{(2)}$. However for complete disease resolution, it is important that there is revitalisation of platelet production.

A recent advancement in this area has been the identification of reticulated platelets or immature platelets. These are newly released platelets which are larger and more reactive than mature platelets and contain RNA. They are the platelet analogue of the red cell reticulocyte and are termed "reticulated" platelets (RPs).

According to some studies on Immature Platelet Fraction (IPF), the percentage of RPs reflects the severity of damage to platelets and the generation of platelets in bone marrow ${ }^{(3)(4)(5)(6)(7)}$. It helps in differentiating between thrombocytopenia related to bone marrow dysfunction and thrombocytopenia related to peripheral platelet consumption $^{(7)}$. The normal range of IPF is 0.7 $4.3 \%{ }^{(4)}$. In patients with bone marrow dysfunction, the IPF level remains low. Platelet recovery in such patients is preceded by rise in IPF. However, in peripheral consumption of platelets, the IPF level remains high and a fall in peripheral destruction is followed by fall in IPF to normal values. Therefore, the estimation of RP's can reflect the rate of thrombopoiesis.

The IPF levels can also predict the timing of platelet recovery which is within 1-2 days of IPF increase $^{(4)(5)}$. Thus, serial assessment of RP's would give a clearer picture about the progress of thrombocytopenia. In India, there are only a few studies on IPF and Platelet recovery and hence there is need for such a study in the Indian setup, which takes into consideration thrombocytopenia of different aetiologies.

\section{Materials \& Methods}

This study was prospective observational study with a sample size of 141 , all of whom were admitted to the Department of Medicine, Jubilee Mission Medical College and Research Institute, Thrissur between December 2015\&June 2016. All cases of thrombocytopenia (platelet count of less than $1,50,000$ cellscells $/ \mu \mathrm{L}$ ) above thirteen years of age were included. All cases of thrombocytopenia (platelet count of less than $1,50,000$ cells $/ \mu \mathrm{L}$ ) below the age of thirteen years Patient's details were collected at the time of admission and were grouped based on clinical diagnosis defined by clinical symptoms. The study group was also classified based on proposed pathophysiology into 1) predominantly bone marrow suppression, 2) predominantly peripheral destruction of platelets, 3) Both bone marrow suppression and peripheral destruction 4) Abnormal pooling of platelets and 5) Unknown causes. All the dengue cases were under group 3. The platelet counts and IPF were obtained using Sysmex XN 1000 Automated haematology analyser at $1^{\text {st }}, 3^{\text {rd }}$ and $5^{\text {th }}$ day following admission for each patient. An increase in platelet value of $>20,000$ cells/ $\mu \mathrm{L}$ from the baseline was considered as platelet recovery (4). IPF values of $>6.1 \%$ was considered as a high IPF ${ }^{(5)}$ and IPF value $<6.1 \%$ was considered as low or normal.

Data were entered in Microsoft Excel 2016 and analysed in SPSS. Descriptive analysis was initially performed. This was followed by inference analysis where the association between change in IPF and change in platelet values during subsequent days was done. 


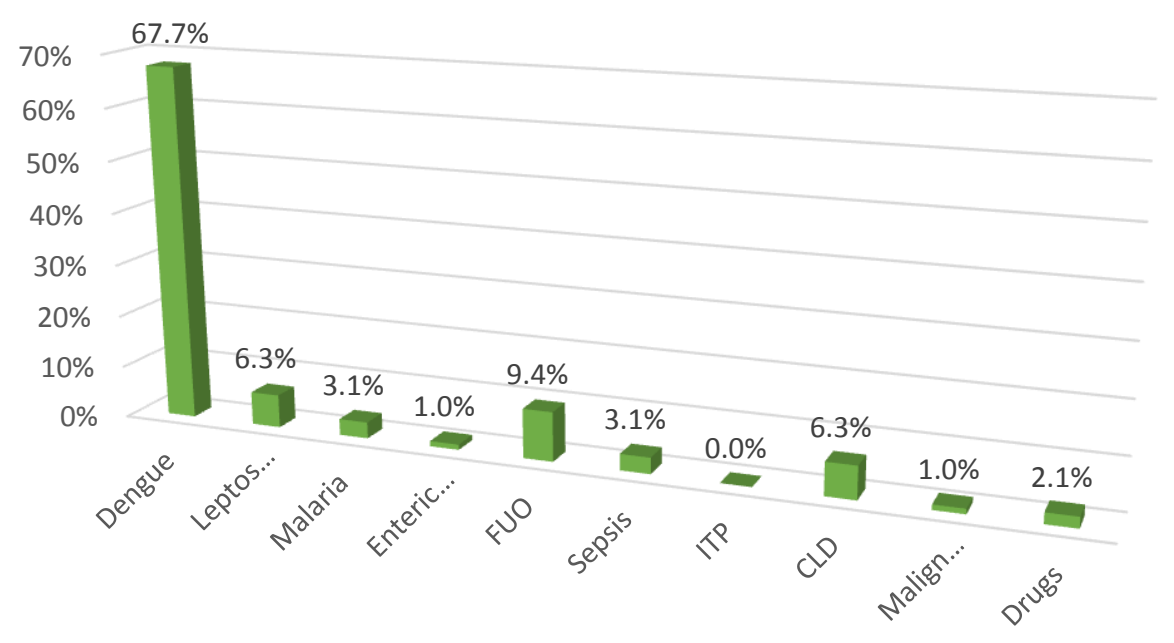

Figure 1 Distribution of Clinical diagnosis in the male patients studied

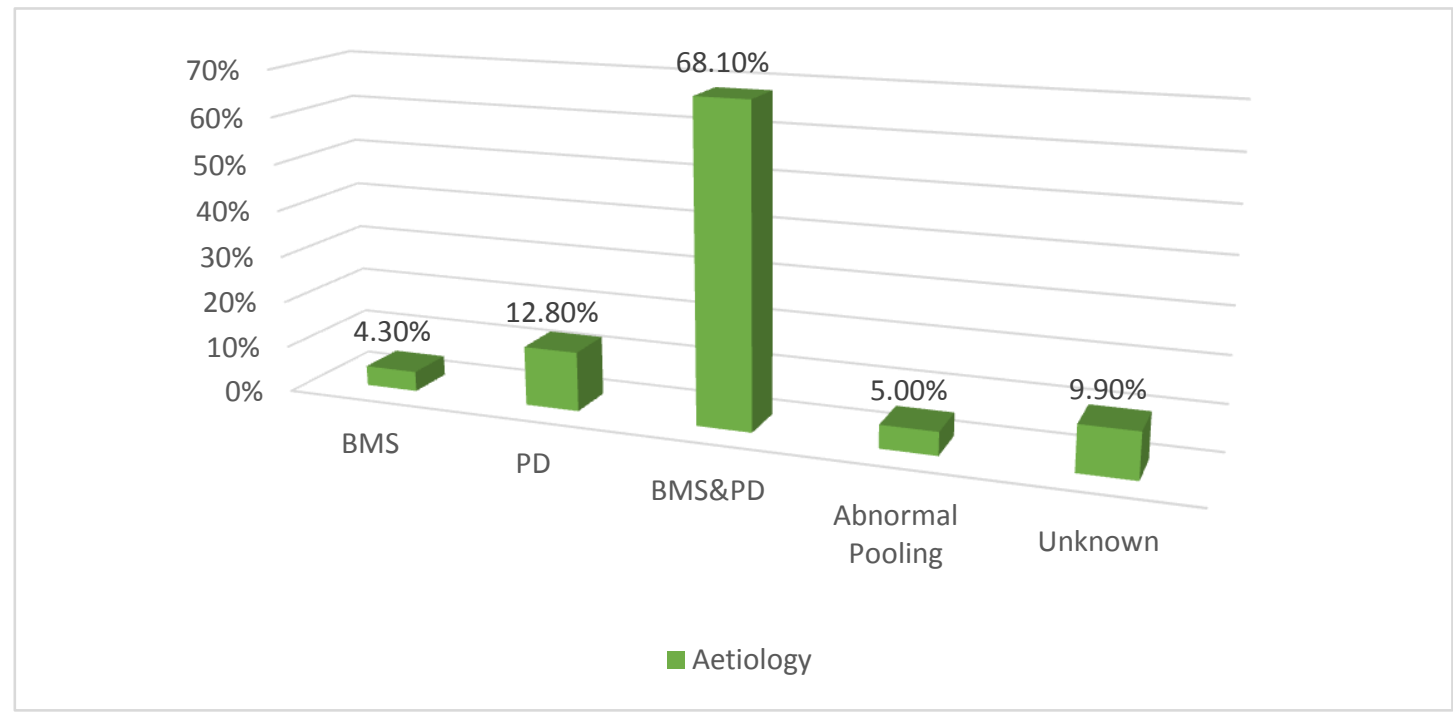

Figure 2 Aetiology of thrombocytopenia of patients studied

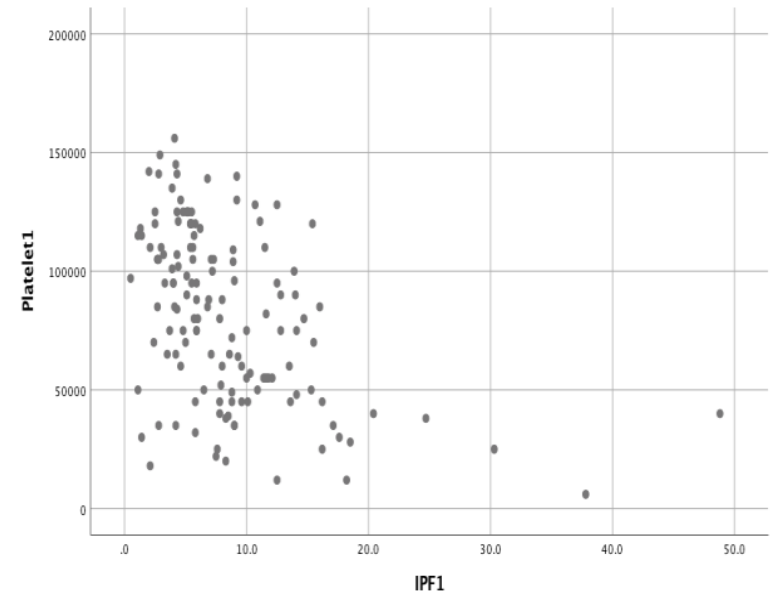

Figure 3 Scatter plot showing non-linear relationship between Platelet counts and IPF on day 1 


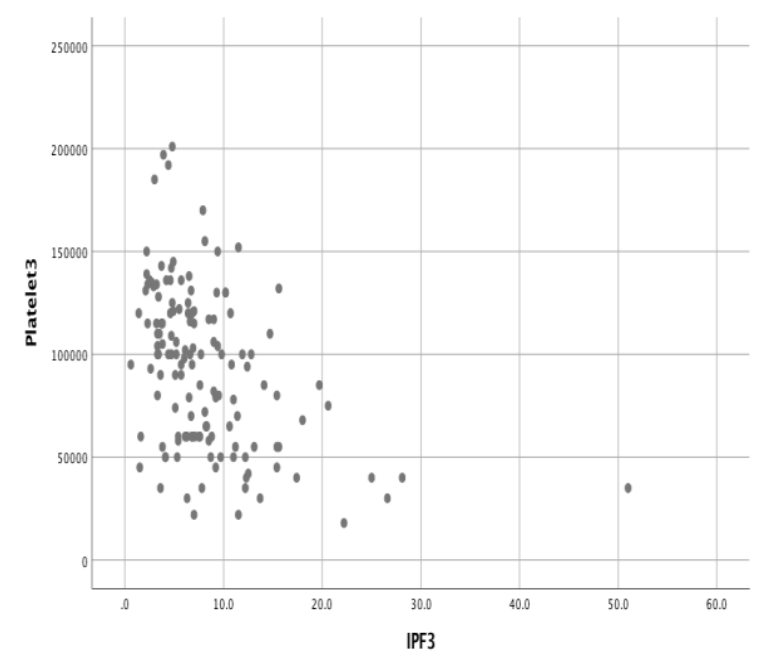

Figure 4 Scatter plot showing non-linear relationship between Platelet counts and IPF on day 3

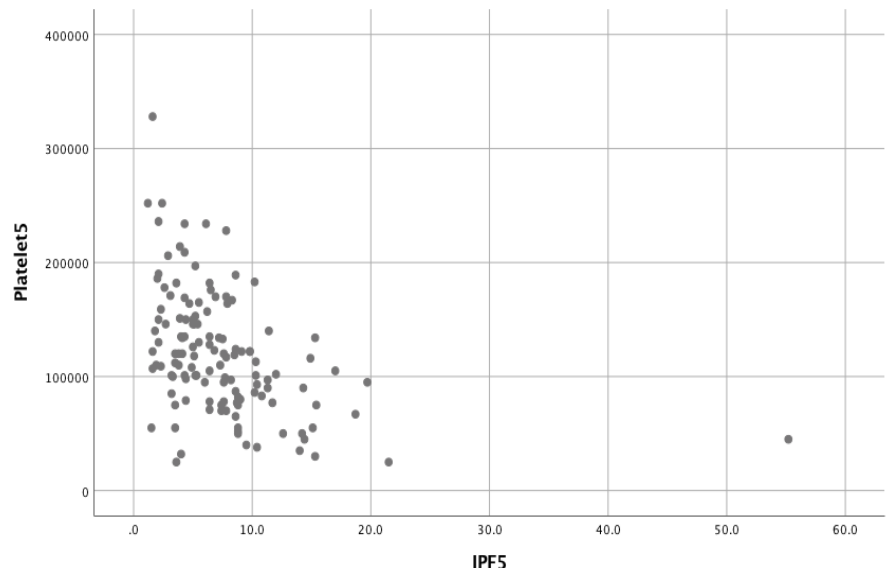

Figure 5 Scatter plot showing non-linear relationship between Platelet counts and IPF on day 5

Table 1 Pearson correlation of IPF with Platelet on Day 1

\begin{tabular}{|l|c|c|c|}
\hline \multirow{2}{*}{ Variable } & \multicolumn{3}{|c|}{ Platelet on Day 1 } \\
\cline { 2 - 4 } & $\mathrm{n}$ & Correlation coefficient & $\mathrm{p}$ Value \\
\hline IPF on Day 1 & 141 & -0.454 & $<0.001$ \\
\hline
\end{tabular}

Table 2 Pearson correlation of IPF with Platelet on Day 3

\begin{tabular}{|l|c|c|c|}
\hline Variable & \multicolumn{3}{|c|}{ Platelet on Day 3 } \\
\cline { 2 - 4 } & $\mathrm{n}$ & Correlation coefficient & $\mathrm{p}$ Value \\
\hline IPF on Day 3 & 141 & -0.425 & $<0.001$ \\
\hline
\end{tabular}

Table 3 Pearson correlation of IPF with Platelet on Day 5

\begin{tabular}{|l|c|c|c|}
\hline Variable & \multicolumn{3}{|c|}{ Platelet on Day 5 } \\
\cline { 2 - 4 } & $\mathrm{n}$ & Correlation coefficient & $\mathrm{p}$ Value \\
\hline IPF on Day 5 & 129 & -0.412 & $<0.001$ \\
\hline
\end{tabular}

Table 4 Pearson correlation of changes in IPF with changes in Platelet count between day 1 and day3

\begin{tabular}{|l|c|c|c|}
\hline Variable & \multicolumn{3}{|c|}{ Platelet Day1-Day3 } \\
\cline { 2 - 4 } & $\mathrm{n}$ & Correlation coefficient & $\mathrm{p}$ Value \\
\hline IPF Day 1- Day3 & 141 & -0.394 & $<0.001$ \\
\hline
\end{tabular}


Table 5 Pearson correlation of changes in IPF with changes in Platelet count between day 1 and day 5

\begin{tabular}{|l|c|c|c|}
\hline \multirow{2}{*}{ Variable } & \multicolumn{3}{|c|}{ Platelet Day1-Day5 } \\
\cline { 2 - 4 } & $\mathrm{n}$ & $\begin{array}{c}\text { Correlation } \\
\text { coefficient }\end{array}$ & $\mathrm{p}$ Value \\
\hline IPF Day1-Day5 & 131 & -0.455 & $<0.001$ \\
\hline
\end{tabular}

Table 6 Pearson correlation of changes in IPF with changes in Platelet count between day3 and day 5

\begin{tabular}{|l|c|c|c|}
\hline \multirow{2}{*}{ Variable } & \multicolumn{3}{|c|}{ Platelet Day3-Day5 } \\
\cline { 2 - 4 } & $\mathrm{n}$ & $\begin{array}{c}\text { Correlation } \\
\text { coefficient }\end{array}$ & $\mathrm{p}$ Value \\
\hline IPF Day3-Day5 & 131 & -0.393 & $<0.001$ \\
\hline
\end{tabular}

Table 7 IPF comparison according to Aetiology of Thrombocytopenia studied with respect to day 1, day 3 and day5

\begin{tabular}{|l|c|c|c|c|c|c|}
\hline \multirow{2}{*}{ IPF } & \multicolumn{5}{|c|}{ Aetiology Thrombocytopenia } & $p$-value \\
\cline { 2 - 6 } & $\begin{array}{c}\text { Bone marrow } \\
\text { suppression }\end{array}$ & $\begin{array}{c}\text { Peripheral } \\
\text { destruction }\end{array}$ & $\begin{array}{c}\text { Both Bone marrow } \\
\text { suppression and } \\
\text { peripheral destruction }\end{array}$ & $\begin{array}{c}\text { Abnormal } \\
\text { pooling }\end{array}$ & $\begin{array}{c}\text { Not } \\
\text { Known }\end{array}$ & \\
\hline Day 1 & $4.78 \pm 2.02$ & $16.16 \pm 12.48$ & $7.52 \pm 4.12$ & $6.71 \pm 6.24$ & $6.50 \pm 2.74$ & $<0.001$ \\
\hline Day 3 & $4.48 \pm 1.11$ & $13.71 \pm 11.92$ & $7.80 \pm 4.40$ & $7.01 \pm 6.77$ & $6.21 \pm 2.85$ & 0.001 \\
\hline Day 5 & $3.73 \pm 1.08$ & $11.63 \pm 12.51$ & $7.00 \pm 3.57$ & $7.40 \pm 7.39$ & $5.68 \pm 2.26$ & 0.015 \\
\hline
\end{tabular}

Table 8 Kruskal-Wallis test (One way ANOVA)

\begin{tabular}{|c|c|c|c|c|}
\hline \multirow{2}{*}{ ETIOLOGY } & \multirow[b]{2}{*}{$\mathbf{n}$} & \multicolumn{2}{|c|}{ IPF } & \multirow{2}{*}{ p Value } \\
\hline & & Mean & SD & \\
\hline Bone marrow suppression & 6 & 4.783 & 2.022 & \multirow{4}{*}{0.003} \\
\hline Peripheral Destruction & 18 & 16.155 & 12.480 & \\
\hline $\begin{array}{l}\text { Bone marrow suppression } \\
\text { peripheral destruction }\end{array}$ & 96 & 7.516 & 4.122 & \\
\hline Abnormal Pooling & 7 & 6.714 & 6.235 & \\
\hline Total & .127 & 8.567 & 6.766 & \\
\hline
\end{tabular}

Table 9 Pair wise comparison

\begin{tabular}{|l|c|c|}
\hline AETIOLOGY & $\boldsymbol{p}$-Value \\
\hline Bone marrow suppression & Peripheral Destruction & $\mathbf{0 . 0 2 1}$ \\
\cline { 2 - 3 } & $\begin{array}{c}\text { Bone marrow suppression and } \\
\text { Peripheral Destruction }\end{array}$ & 1.000 \\
\cline { 2 - 3 } & Abnormal Pooling & 1.000 \\
\hline Peripheral Destruction & $\begin{array}{c}\text { Bone marrow suppression and } \\
\text { Peripheral Destruction }\end{array}$ & $\mathbf{0 . 0 1 1}$ \\
\cline { 2 - 3 } & Abnormal Pooling & $\mathbf{0 . 0 4 5}$ \\
\hline $\begin{array}{l}\text { Bone marrow suppression and } \\
\text { Peripheral Destruction }\end{array}$ & Abnormal Pooling & 1.000 \\
\hline
\end{tabular}

\section{Results}

The study included 141 subjects of which $68.1 \%$ were males and $31.9 \%$ were females. Majority of patients belonged to age group 21-40 years. (42.6 $\%$ ) Dengue was the most common clinical diagnosis in the study with $68.1 \%$ of the subjects being diagnosed with the same. Subjects were grouped into various clinical diagnosis which included dengue, leptospirosis, malaria, enteric fever, sepsis, idiopathic thrombocytopenia, chronic liver disease, malignancy and drug induced thrombocytopenia (Figure 1).

IPF was significantly high in the patients with Idiopathic Thrombocytopenic Purpura, mean was $26.1 \%$ (9 to 48.8 ).

Analysis of the data revealed an association 
between IPF and Platelet Levels with a $p$-value of $<0.01$. Analysis on Day 1, 3 and 5 levels of IPF and Platelets shows an inverse correlation with a correlation coefficient (r) of $-0.454,-0.425$ and 0.412 respectively. (Tables 1,2, and 3). When change in IPF was compared with change in platelets, it also showed a moderate negative correlation (Tables 3, 4 and 5).

IPF is shown to have statistical significance when compared to aetiology of thrombocytopenia.The aetiological classification was based on the proposed pathophysiology of thrombocytopenia in each clinical diagnosis. Kruskal-Wallis test (one way ANOVA) which is a nonparametric test was applied to know if there was any significant difference in IPF among the aetiologies of thrombocytopenia (Table 8). The $p$ - value obtained was 0.003 which was statistically very significant. It showed that there was a significant difference in IPF among the aetiologies. Further analysis like pair wise comparison was done between all groups which showed that peripheral destruction of platelets when compared with all other aetiology groups had a significant $p$-value (Table 9). The $p$-value was found to be $<0.05$ which suggests that there is a significant association between IPF levels and platelet destruction. In all other aetiologies p-value was not significant.

\section{Discussion}

Immature Platelet Fraction (IPF) is a measure of reticulated platelets found in the peripheral circulation. It is a relatively new parameter which can potentially be used to assess the change in platelet levels which could in turn be used to assess the prognosis of a thrombocytopenic state. This study aimed to find whether IPF can be used as a prognostic indicator in thrombocytopenia.

This study showed a moderate negative correlation between IPF and platelet. Thus, IPF has some predictive value indicating compensatory platelet production. This is in accordance with previous studies by Abe et al $(2006)^{(9)}$, Saigo et al $2008^{(10)}$ and Cremer et al
$2009^{(11)}$. In all these studies, a negative correlation was established between IPF and platelets in both adults and children.

This relationship could be due to the phenomenon called immature platelet shift. This is similar to reticulocyte shift which is seen when more immature forms of reticulocytes are released into the circulation as in anaemia. Thus, the time taken for reticulocytes to lose their reticulum, the "reticulocyte lifespan" is increased ${ }^{(12)}$

Cybulska et al found an inverse correlation was found between platelets and IPF levels in all aetiologies. This correlation was obtained in this present study as well. However, Cybulska et al also found that there was a broad overlap of immature platelet measurements in ITP and bone marrow failure patients. They concluded that IPF has limited value in the diagnosis of thrombocytopenia of different aetiologies ${ }^{(12)}$. However in this study a significant association between IPF levels and platelet destruction was found when compared to other aetiologies. In a study by Pons et $\mathrm{al}^{(14)}$, they had established a good correlation between IPF and reticulated platelets in thrombocytopenia due to peripheral destruction. A significant association between IPF and Dengue was not observed in our study despite dengue being majority $(68.1 \%)$. This may be due to the coexistence of both bone marrow suppression and peripheral destruction in dengue fever (4) (13). However, in a study conducted by Dadu et al (2013) on Dengue patients found that IPF had a strong correlation with the recovery of platelet counts $^{(4)}$

In other aetiologies like bone marrow suppression and abnormal pooling, a statistically significant correlation was not obtained. This could be because the number of patients in both groups were small. It may also be due to an overlap of pathophysiology of thrombocytopenia in bone marrow suppression and abnormal pooling.

\section{Conclusions}

There was a moderate inverse correlation between IPF and platelet recovery when all aetiologies 
were considered. As IPF fell, platelets tend to increase. In cases with peripheral destruction of platelets as an aetiology, there was a significant association with IPF. Hence further research needs to be conducted to study this association.IPF was not found to be a significant prognostic indicator in dengue.

\section{References}

1. Konkle BA. Disorders of Platelet and Vessel Wall. In Kasper DL, Hauser SL, Jameson JL, Fauci AS, Longo DL, Loscalzo J. Harrison's Principles of Internal Medicine. Newyork: McGraw Hill; 2015; 725.

2. Watson HG, Craig JIO, Manson LM. Blood disease. In Walker BR, Colledge NR, Ralston SH, Penman ID. Davidson's Principles \& Practice of Medicine. 22nd ed. Edinburgh: Churchill Livingstone Elselvier; 2014;1007-8.

3. Briggs C, Kunka S, Hart D, Oguni S, Machin SJ. Assessment of an immature platelet fraction (IPF) in peripheral thrombocytopenia. British Journal of Haematology. 2004 July; 126(1):93-9.

4. Dadu T, Sehgal K, Joshi M, Khodaiji S. Evaluation of the immature platelet fraction as an indicator of platelet recovery in dengue patients. International Journal of Laboratory Hematology. 2014 October; 36(5): 499-504.

5. Suman F, D'Cruze L, Rajendran R, Varadarajan S. Dengue:platelet and immature platelet dynamics a study done at a tertiary care centre from South India. International Journal of recent trends in science and technology. 2014; 12(3): 6203.

6. De Blasi R, Cardelli P, Costante A, Sandri M, Mercieri M, Arcioni R. Immature platelet fraction in predicting sepsis in critically ill patients. Intensive Care Medicine. 2013 April; 39(4):636-43.
7. Van der LN, Klinkenberg LJ, Meex SJ, Beckers EA, deWit NC, Prinzen L. Immature Platelet fraction measured on sysmex XN hemocytometer predicts thrombopoietic recovery after autologous stem cell transplantation. Eur J Haematol. 2014; 93(2):150-6.

8. Hulley SB, Browner WS,Newman TB. Estimating Sample Size and Power: Applications and Examples. In: Hully SB, Cummings SR, Browner WS, Grady DG, Newman TB, editors. Designing Clinical Research. $\quad 3^{\text {rd }}$ Edition. Philadelphia: Lippincott Williams \&Wilkins;2007;89.

9. Abe Y, Wada H, Tomatsu H, Sakaguchi A, Nishioka J, Yabu Y, Onishi K. A simple technique to determine thrombopoiesis level using immature platelet fraction (IPF). Thrombosis research. 2006; 118:463-9.

10. Saigo K, Sakota Y, Masuda Y, Matsunaga K, Takenokuchi M, Nishimura K, Sugimoto T, Sakurai K , Hashimotto M, Yanai T, Hayakawa A, Takeshima Y, Nomura T, Kubota Y, Kumagai S. Automatic detection of immature platelets for decision making regarding platelet transfusion indications for pediatric patients. Transfusion and Apheresis Science. 2008; 38:127-32.

11. Cremer M, Paetzold J, Schmalisch G, Hammer $\mathrm{H}$, Loui A, Dame $\mathrm{C}$, et al. Immature platelet fraction as novel laboratory parameter predicting the course of neonatal thrombocytopenia. British Journal of Haematology. 2009 February; 144(4):619-21.

12. Cybulska A, Meintker L, Ringwald J, Krause SW. Measurements of immature platelets with haematology analysers are of limited value to separate immune thrombocytopenia from bone marrow failure. British Journal of Haematology. 2017 May; 177(4): 612-9.

13. Bhalla A, Bagga R, Dhaliwal L, Sharma R, 
Varma S. Steroid responsive prolonged thrombocytopenia in dengue. Indian Journal of Medical Sciences Mumbai. 2010 February; 64(2):90-3.

14. Pons I, Monteagudo M, Lucchetti G, Munoz L, Perea G, Colomina I, et al. Correlation between immature platelet fraction and reticulated platelets. Usefulness in the etiology diagnosis of thrombocytopenia. European Journal of Haematology. 2010 August; 85(2):158-63. 